Research, part of a Special Feature on Assessing Risks to Wildlife

\title{
Understanding the Risk to Neotropical Migrant Bird Species of Multiple Human-Caused Stressors: Elucidating Processes Behind the Patterns.
}

\author{
Ralph S. Hames $^{1}, \underline{\text { James D. Lowe }}^{1}, \underline{\text { Sara Barker Swarthout }}^{1}$, and Kenneth V. Rosenberg ${ }^{1}$
}

\begin{abstract}
Ubiquitous human-caused changes to the environment act as multiple stressors for organisms in the wild, and the effects of these stressors may be synergistic, rather than merely additive, with unexpected results. However, understanding how focal organisms respond to these stressors is crucial for conservation planning for these species. We propose a paradigm that alternates extensive, broadscale data collection by volunteer collaborators to document patterns of response, with intensive fine-scale studies by professional researchers, to elucidate the processes underlying these patterns. We demonstrate this technique, building on our existing work linking patterns of population declines in the Wood Thrush (Hylocichla mustelina) to synergistic effects of acid rain and habitat fragmentation. To better understand the processes behind these patterns, we use a simple protocol to explore linkages between acid rain, leaching of calcium from the soil, and declines in the abundance of calcium-rich invertebrate prey species, which may be necessary for successful breeding by this thrush. We sampled at 40 study sites across New York that were chosen based on estimated acid deposition and soil properties. Our results show that the calcium content of the soils sampled is proportional to the soil $\mathrm{pH}$, that the abundance of calcium-rich invertebrate prey tracks soil properties, and that the presence of a breeding Wood Thrush was correctly predicted in $>70 \%$ of study sites by the biomass of calcium-rich prey, and in particular, the biomass of myriapods (Diplopoda). We show that a simple repeatable protocol, suitable for use by volunteers across broad geographic extents and ranges of habitat fragmentation, can help us understand the reactions of some forest birds to acid rain in combination with habitat fragmentation. We detail the development of this protocol for volunteers in the Birds in Forested Landscapes project, and describe future plans.
\end{abstract}

Key Words: Multiple scales; synergistic effects; citizen science; habitat fragmentation; acid rain; forests; anthropogenic change; soil; calcium; invertebrates

\section{INTRODUCTION}

Human-caused changes to the environment are ubiquitous. These changes, which often occur at multiple scales or geographic extents simultaneously (Andrén 1994, Donovan et al. 1997, Baillie et al. 2000, Boulinier et al. 2001, Hames 2001, Lee et al. 2002, Sih et al. 2004), can result in multiple sources of stress for organisms in the wild (Landis 2003). Focusing solely on one aspect of anthropogenic change to the environment may lead to a less than optimal understanding of human-altered natural processes and can lead to poor predictions of response to such change, thus, leading to poor management decisions (Spalding et al. 2000, Heugens et al. 2001, Moore 2001, Fair and Ricklefs 2002, Hames et al. 2002a, Driscoll et al. 2003, Sih et al. 2004). Further, multiple stressors may behave synergistically, with combined effects that are not merely additive but also multiplicative (Hames et al. 2002a).

Without insight into the multiple influences on focal species or communities, management decisions may have unexpected results. Understanding the mechanisms of anthropogenic change to provide this insight may require both broadscale, i.e., large geographic extent, observational studies to show the patterns of response by populations and communities, as well as fine-scale, i.e., typically over a small extent, and observational or manipulative, studies to explore the processes that lead to the larger patterns (Hames 2001). Insights gained from these fine-scale studies can then lead 
to further hypotheses that can be tested in broadscale observational studies (Fig. 1). The iterative alternation of broadscale and fine-scale studies has considerable promise as an approach for understanding multiple stressors of organisms in the wild.

We present an example of research that uses this approach to understand the combined effects of habitat fragmentation and acid rain on the Wood Thrush (Hylocichla mustelina) breeding in eastern North American forests (Hames et al. 2002a). This approach is made possible, in large part, by the use of extensive data collected by volunteer citizen scientists across eastern North America (Hames et al. 2001, Sauer et al. 2001, Hames et al. 2002b, Hames et al. 2002a). These data show a broadscale pattern of declining probability of breeding by the Wood Thrush, particularly when acid rain and forest fragmentation co-occur and when thrush abundance is highest (Hames et al. 2002a).

We show the results of a fine-scale, tightly focused study that we carried out in New York to elucidate the processes behind these patterns such as the mechanisms by which soil acidification can impact calcium-rich prey needed by breeding thrushes, while holding habitat fragmentation constant. We also describe the development of a protocol, suitable for use by volunteers across wide geographic extents and varying amounts of fragmentation, to enumerate the presence of calcium-rich prey needed for breeding by many birds, based on these results.

\section{Habitat fragmentation}

Habitat fragmentation occurs when large, contiguous blocks of habitat for a given organism are subdivided into smaller, disjunct blocks by roads, railways, power line right-of-ways, and other human development (Andrén 1994). At the landscape level, fragmentation results in a decreasing amount of habitat (Andrén 1994). For forest nesting birds, this typically results in concomitant decreases in the number of individuals in the landscape (Andrén 1994). Fragmentation changes the remaining habitat by decreasing mean size and increasing isolation of forest patches from other forest patches (Andrén 1994). Fewer individuals in the landscape also means that there are fewer potential immigrants to these small, isolated patches in which the risks of local extinction are higher, even if the local habitat is otherwise suitable (Hames et al. 2001, Weathers et al. 2001).

In addition to these so-called biogeographic effects (Saunders et al. 1991), fragmentation increases the amount of less suitable forest edge habitat and decreases core habitat in the landscape. This may lead to increases in generalist predators and the nestparasitic Brown-headed Cowbird, Molothrus ater (Donovan et al. 1997, Rosenberg et al. 1999). Surprisingly, the amount of edge habitat in the landscape may also influence whether some birds choose to nest in patches within it (Hames et al. 2001).

At the patch level, fragmentation increases the ratio of edge, which has higher rates of predation parasitism and atmospheric deposition, to core habitat (Paton 1994, Bellamy et al. 1996, Donovan et al. 1997). Fragmentation can also lead to a warmer, drier microclimate at the edge of the patch. The altered airflow at edges also enhances atmospheric deposition of a number of substances (Weathers et al. 2001). Thus, within the edge zone, i.e., $50-150 \mathrm{~m}$ from the forest-nonforest edge, atmospheric deposition of pollutants such as acidifying ions, heavy metals, and pesticides (Weathers et al. 1995, Weathers et al. 2001) is enhanced. However, fragmentation is but one anthropogenic change to forest ecosystems.

\section{Acid rain}

The abundance of some bird species in otherwise suitable habitat has been shown to be negatively correlated with the atmospheric wet acidic deposition, such as acid rain (Graveland et al. 1994, Dekhuijzen and Schuijl 1996, James et al. 1996, Zang 1998, Hames et al. 2002a). Acidic wet deposition may leach bases from well-drained soils such as calcium, which is needed by forest songbirds to produce a clutch of eggs when breeding (Blancher and McNicol 1991, Graveland et al. 1994, Graveland 1996, Graveland and van der Wal 1996, Graveland 1998, Bures and Weidinger 2003). This depletion of soil pools of calcium can lead to a decrease in calcium-rich invertebrates, i.e., myriapods, isopods, and gastropods, that live in the forest leaf litter (Bures and Weidinger 2003).

These invertebrates, taken as prey by forest nesting birds, may be an important source of calcium, necessary for breeding (Graveland and Vangijzen 1994, Graveland and van der Wal 1996, Bures and 
Fig. 1. Schematic showing alternating extensive, broadscale and intensive, fine-scale studies to address multiple stressors over multiple geographic extents. Broadscale, volunteer-based studies allow the documentation of patterns of population-level response to stressors, whereas fine-scale intensive studies can elucidate the processes that lead to observed patterns. Fine-scale studies are also used to develop and test protocols for broadscale studies.

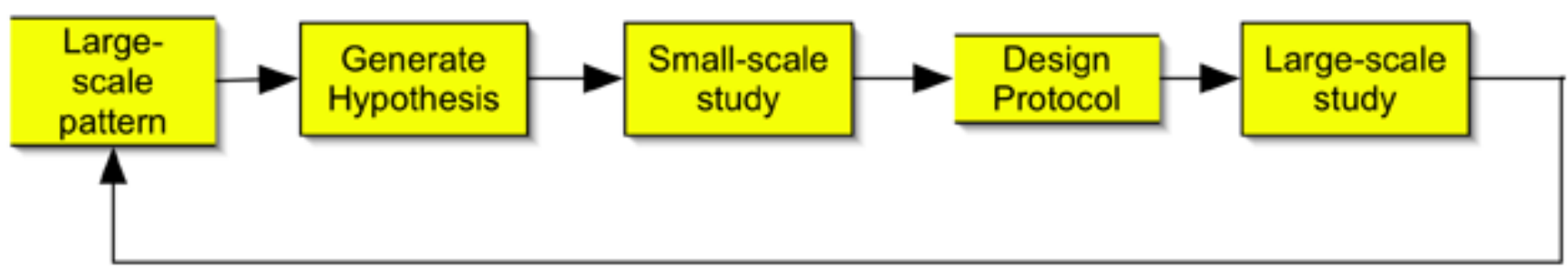

Weidinger 2003), particularly for insectivorous and granivorous birds that cannot sequester sufficient calcium from their normal diet to successfully lay a clutch of eggs and raise chicks to fledging (Graveland 1996, Graveland and van der Wal 1996, Nybo et al. 1997). Even if birds were able to lay a clutch of eggs, both the eggs themselves and the clutches were smaller, as was the wing length of the young before hatching, and fewer young were fledged per nest (St. Louis and Barlow 1993) when soil calcium concentration was low and calciumrich prey were scarce. Finally, even if the adults are able to overcome these handicaps, they may do so at the cost of their own condition, flying further to procure the calcium supplements needed by their brood (St. Louis and Breebaart 1991) and ending the breeding season in poorer condition (Wasson 2002, Mand and Tilgar 2003). This may substantially affect their survival or the probability of their return to breed at a given location (Eeva and Lehikoinen 1998).

Acidification may also mobilize toxic metals such as aluminum, lead, cadmium, and mercury (Scheuhammer 1991, St. Louis et al. 1993), increasing their availability. In the presence of decreased dietary calcium, both the uptake and the toxicity of these metals are enhanced (Scheuhammer 1991, Silver and Nudds 1995, Scheuhammer 1996), leading to behavioral abnormalities (Silver and Nudds 1995), ataxia, and in some cases, death (Spalding et al. 2000).

\section{Acid rain and the Wood Thrush}

The Wood Thrush is a Neotropical migrant bird that breeds widely in the forests of eastern North America and winters from southeastern Mexico to Guatemala (Roth et al. 1996). It is a nearly ubiquitous breeder in eastern North America and remains fairly abundant in deciduous and mixed forests with a well-developed understory, a leaf litter layer, and some moisture. It feeds mainly on invertebrates, for which it forages in the leaf litter (Holmes and Robinson 1988), and fruit in season (Roth et al. 1996). From 1966 to 2003, Wood Thrush has declined across its range at a rate of $1.8 \% / \mathrm{yr}$, with declines of up to $4.1 \% / y r$ in regions such as the Adirondack mountains (Sauer et al. 2004), for an overall decline of nearly $50 \%$.

Our work has demonstrated that after statistically correcting for a number of other influences, a site receiving high levels of acid rain is much less likely to contain a nesting Wood Thrush (Hames et al. 2002a). Further, Hames et al. (2002a) demonstrated a multiplicative or synergistic interaction that increased the negative effect of acidification in the presence of forest fragmentation. The data used for this analysis include records of wet atmospheric deposition of acidifying ions from the National Atmospheric Deposition Program (Lamb and Bowersox 2000), soil pH data from the STASGO database from the Natural Resource Conservation Service (USDA/NRCS 1994), as well as regional abundance of the Wood Thrush from the Breeding Bird Survey (Hames et al. 2002a, Patuxent Wildlife 
Research Center 2000).

Data from the Cornell Laboratory of Ornithology's Birds in Forested Landscapes (BFL) project were central to our analysis (Hames et al. 2002a,b). BFL provided data on presence or absence of Wood Thrush breeding attempts in a given study site, which was the response variable for our regression analysis. Other data, simultaneously collected at several spatial scales by BFL's volunteer participants, were used in our analysis. At the level of the landscape, these data included the proportion of forest and edge index, a measure of the amount of forest/nonforest-edge habitat in the 1000-ha block surrounding the study site. Additionally, the volunteer participants gathered data at the level of the forest patch within the study site, including the hydrology and topography, the type and structure of vegetation, as well as the presence of predator and competitor species.

Although Hames et al. (2002a) demonstrated decreased probability of breeding in the presence of acidification, after statistically adjusting for a number of other factors, the processes underlying the observed pattern remain unclear. However, a substantial body of work from Europe links bird declines to the depletion of soil pools of calcium caused by acidification, and sharp declines in the availability of calcium-rich invertebrate prey (Graveland et al. 1994, Dekhuijzen and Schuijl 1996, Graveland and van der Wal 1996, Graveland and Drent 1997, Graveland 1998, Weimer and Schmidt 1998, Bures and Weidinger 2000).

To test whether declines in the Wood Thrush are related to a similar scarcity of calcium-rich prey caused by acid rain, we studied the occurrence of the Wood Thrush, as well as soil properties and the abundance of calcium-rich prey species in the leaf litter at 40 forest sites, with little fragmentation, throughout New York in 2002.

Our goal was two-fold: first, we wanted to test whether a positive relationship existed between soil properties such as $\mathrm{pH}$ and extractable calcium, the abundance of calcium-rich prey, and the presence of a territorial Wood Thrush; second, we wanted to develop a protocol that could be reliably executed by volunteers, thus, giving us the potential to sample calcium-rich prey at hundreds of sites throughout the Wood Thrush's range. The crucial requirements for the protocol were simplicity, repeatability, and lack of bias. Because our focus was on the role played by calcium-rich prey species at sites with acidified soils, we intentionally controlled for fragmentation by choosing study sites in contiguous blocks of forests in this study, i.e., relatively unfragmented landscapes. The methods developed in this small-scale study are planned for use by volunteers at hundreds of sites across a range of fragmentation values.

\section{METHODS}

\section{Study sites and thrush sampling}

We chose ten sites in each of four areas of New York, the Finger Lakes, Ithaca area, the foothills of the Catskill mountains, Brookfield area, the Tug Hill plateau, and the Saranac Lake area in the Adirondacks (Fig. 2), using USGS topographic maps and then site visits to confirm suitability. These regions were chosen based on their underlying geology, soil properties, and estimated acid deposition regimes after Hames et al. (2002a), to capture the widest possible range in variation in these variables. Because our focus was to elucidate the underlying processes behind the patterns demonstrated in Hames et al. (2002a) and, in particular, the role played by calcium-rich prey, we intentionally chose sites in large, contiguous blocks of forest, i.e., in landscapes with little fragmentation. Within each area, sites were grouped into two subareas of five sites each intended to capture a range of soil types.

To ensure access, we placed most of the sites in public lands and for efficiency of sampling, mostly within $250 \mathrm{~m}$ of three-season, unpaved, forest access roads with little traffic. At most sites, the road did not constitute a gap in the canopy, and thrushes were frequently observed to cross these roads (Hames, personal observation). All sites were located in mature deciduous or mixed forest, a moist soil, a well-developed understory and leaf litter layer, and $<30 \%$ of the canopy was made up of needle-leaved trees (Roth et al. 1996). Each study site consisted of a circle, each with a radius of 150 $\mathrm{m}$ and approximately 7 ha. All sites were between 200 and $500 \mathrm{~m}$ above mean sea level, well within 
the elevation range of the breeding Wood Thrush (Roth et al. 1996).

\section{Soil sampling and analysis}

We collected soil samples at each site, taking cores of the top $5 \mathrm{~cm}$ of the soil using a marked stainlesssteel soil corer. Three cores were taken at each site, one at the center of the study site, and one each at $\sim 3 \mathrm{~m}$ in a randomly chosen direction from the two cardboard traps. We first removed all of the leaflitter away from the subsampling site, i.e., to bare soil, and then we placed the cores in labeled, brown paper bags. We then allowed the three subsamples to air dry, removed all stones, twigs, and roots, and ground the soil by hand so that it could pass through a $2 \mathrm{~mm}$ sieve. Each subsample was then weighed, and equal masses from each of the three subsamples were bulked, forming the sample for a given site.

Processed soil samples were analyzed by the Cornell Nutrient Analysis Laboratory for the concentrations of $\mathrm{Ca}, \mathrm{Mg}, \mathrm{Al}, \mathrm{Cu}, \mathrm{Fe}, \mathrm{Mn}, \mathrm{Zn}$ and cation exchange capacity (CEC) using extraction in $\mathrm{NH}_{4} \mathrm{Oac}$ (buffered to $\mathrm{pH}$ 7.0) and unbuffered $\mathrm{NH}_{4} \mathrm{Cl}$, followed by atomic absorption. Additionally, the $\mathrm{pH}$ of the soil in deionized water and moisture content of the soil was determined. The organic matter content was determined by the loss on ignition method (OM-LOI). For each region, we submitted two identical validation samples. Each sample was given a different sample number so that we could check on the consistency of the laboratory.

\section{Invertebrate sampling}

At each site, we sampled calcium-rich invertebrate prey species that could serve as sources of calcium for the Wood Thrush during the breeding season, $i$. e., the time of highest calcium demand. These invertebrates included snails (Gastropoda) whose shells contain calcium, as well as isopods (Crustacea), and millipedes (Diplopoda) whose carapaces are largely calcium carbonate (Bures and Weidinger 2003). We also recorded the presence of earthworms (Annelida) and slugs (Gastropoda) which do not contain large amounts of calcium but which need calcium to reproduce, and may additionally serve as an important source of protein for forest breeding birds (Hawkins et al. 1997).

At each site, we placed two wet cardboard traps (Hawkins et al. 1998, Oggier et al. 1998, McCoy
1999), which consisted of a $30.5 \times 30.5 \mathrm{~cm}$ piece of uncoated, corrugated cardboard that we had wetted by pouring $1 \mathrm{~L}$ of non chlorinated water slowly over one side. We then placed the cardboard wet side down in the wet spot from water poured on the "trap" and, finally, weighted it down with stones or sticks. Traps were placed in the late afternoon or evening and checked, in the order they were set, the following morning before 10:00 am EST, because preliminary data collection showed a sharp drop in the number of invertebrates captured after about 10:00 EST (Hames, unpublished data). At each trap, we recorded all gastropods, including slugs, all isopods, myriapods, and annelids (earthworms) on the traps and on the surface of the leaf litter beneath them, and then collected them. Collected prey items were preserved in ethyl alcohol until they were decanted, dried in a desiccating oven, and weighed on a Satorius Model 2PCP microbalance.

\section{Thrush sampling}

We used the tested BFL protocol to sample for breeding Wood Thrushes, making two visits to each site, one timed to coincide with pair bonding and the other with brood rearing. On each visit we conducted a 10-min point count for the detection of the focal species and predators, either visually or audibly, based on spontaneous vocalizations. After the point count, we used playback of conspecific songs and calls to elicit a response from territorial birds. Finally, we used playback of a flock of small birds, mostly Black-capped Chickadees, Poecile atricapilla, mobbing a small owl (Gunn et al. 2000) to attract birds in the vicinity. A more detailed description of the methodology is available in Hames et al. $(2002 a, b)$. We used standardized breeding atlas codes to classify breeding attempts, i.e., possible, probable, confirmed, based on behavior of birds that we detected (Butcher and Smith 1986).

\section{Statistical analysis}

We examined the distribution of all variables to check for errors and outliers, and transformed the variables to meet the assumptions of the analytical methods used, generally approximate normality. All analyses were carried out using StatView (SAS Institute 1998) and SAS statistical software (SAS Institute 1996). We used Analysis of Variance (ANOVA) to test for differences in the means of 
Fig. 2. Map showing the location of 40 study sites in New York. Sites were selected in four areas, i.e., the Adirondacks, the Tug Hill Plateau, the Finger Lakes region, and the Brookfield area in the Reforestation District, south of Utica. These all differed in geological parent material, soil properties, and estimated wet acidic deposition using maps. Within each area, two groups of five sites were placed in two widely separated locations to further ensure that a range of soil properties were sampled.

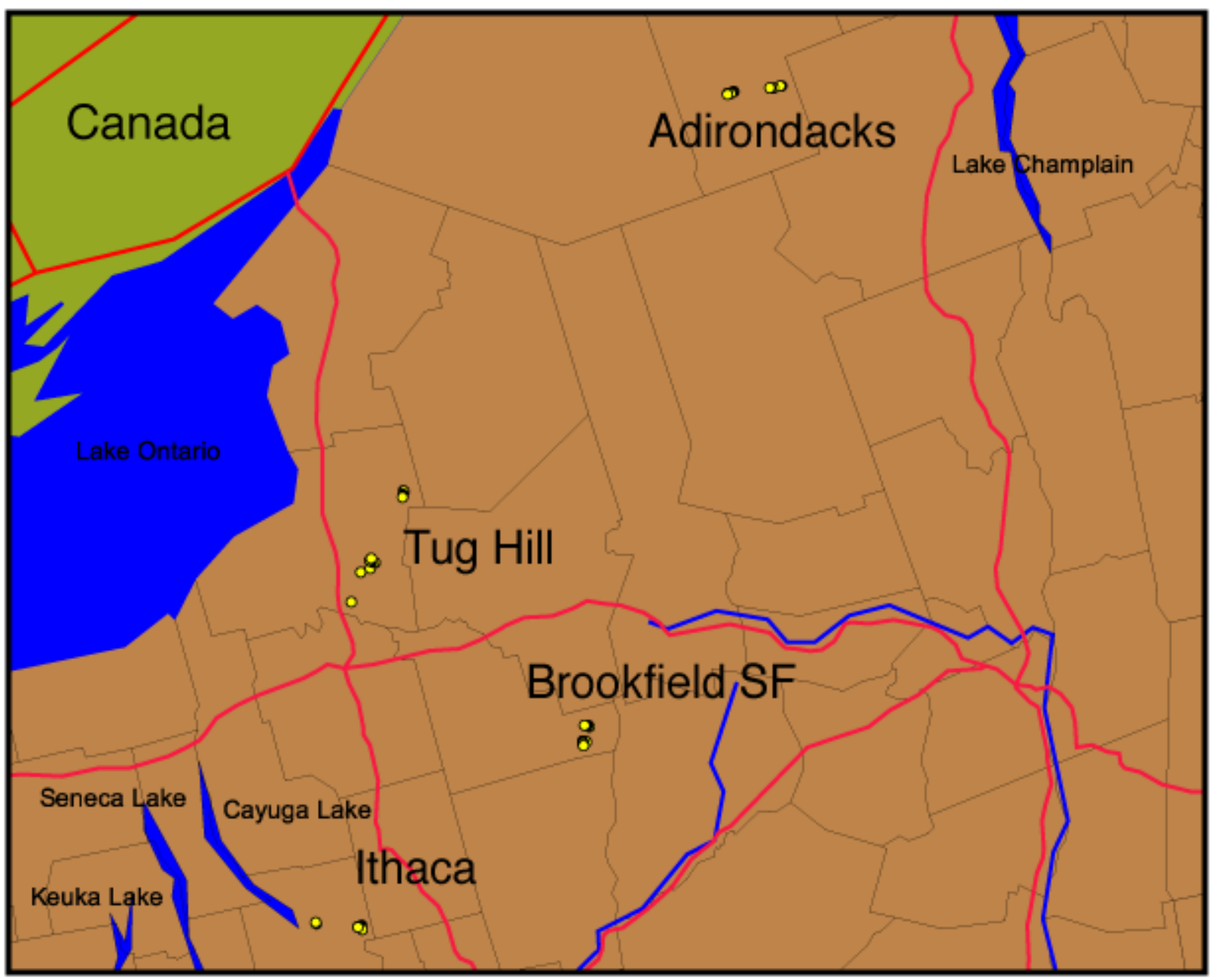

soil variables and invertebrate masses between regions and tested for pairwise differences in the means using contrasts (Fisher's PLSD). For analyses of relationships between continuous variables, such as soil properties, we used ordinary least squares linear regression, after any necessary transformation of the predictor and response variables. After fitting the model, we plotted the residuals against the fitted values to check for inequality of variance.

We also used logistic regression to model the probability that a site would be occupied by a breeding Wood Thrush, based on soil properties and the presence of calcium-rich prey. After fitting each model, we used confusion matrices to examine the 
performance of our logistic regression models at correctly predicting the presence and absence of breeding Wood Thrushes. For each model we calculated the area under the curve (AUC) statistic derived from receiver operating characteristic curves (Hames 2001, Manel et al. 2001, Hall and St. Louis 2004), a measure of classifier performance unaffected by prevalence, percent of presences and correctly classified, and Cohen's Kappa, a measure of the classifier's improvement over the number of sites expected to be classified correctly by chance (Cohen 1960, Hames 2001).

\section{RESULTS}

\section{Soil sampling}

Soil properties were variable. In fact, the withinregion variation in soil properties was often larger than the between-region variation, in contrast to the wide regional differences in thrush detections, and in the abundance of calcium-rich prey. For brevity, we will omit most of the results of the soil sample analysis and focus on the results of the ammonium acetate buffered extraction of soil calcium and the measurement of $\mathrm{pH}$ of the soil in deionized water. Calcium content of the samples (mean \pm SE) was $730.7 \pm 82.3 \mathrm{mg} / \mathrm{kg}$, and there were no significant differences between the means among the four study regions $\left(F_{3,34}=0.36, P=0.7823\right)$.

Significant between-region differences in the means did occur for some soil properties. For example, soil $\mathrm{pH}$ showed significant differences between regions $\left(F_{3,34}=3.283, P=0.033\right)$, with an overall mean \pm SE of $4.15 \pm 0.09$ and a wide range, (3.54-5.81). No soil samples were circumneutral, and the highest recorded $\mathrm{pH}$ of 5.81 was an outlier. The Ithaca region had soils with a significantly higher mean $\mathrm{pH}$ than either the Adirondacks (Fisher's protected least square difference $(\mathrm{PLSD})=0.577, P=0.019$ ) or the Tug Hill regions (PLSD $=0.688, P=0.006)$.

\section{Invertebrate sampling}

The number of calcium-rich potential prey items counted using the cardboard traps ranged from a minimum of zero to a maximum of 74 . The number of prey per trap was $15.6 \pm 3.41$ (mean \pm SE) and the median was 5.0. The number of prey items at the two traps, within a site, showed a high degree of correspondence $(Z=6.002, P<0.0001, r=0.60)$. ANOVA showed no significant effect of region on the natural log of the total number of calcium-rich prey $\left(F_{3,34}=1.61, P=0.206\right)$. However, the effect of region on the mean number of gastropods was marginally significant $\left(F_{3,34}=2.78, P=0.0561\right)$ and Tug Hill had a significantly higher mean than either the Adirondacks (PLSD $=1.189, P=0.0391$ ) or the Ithaca area $(\mathrm{PLSD}=1.456, P=0.0184)$.

Finally, region showed a significant effect $\left(F_{3,34}=\right.$ $6.143, P=0.0019)$ on the log-transformed total mass of calcium-rich prey, isopods, myriapods and gastropods. The Adirondacks had the lower mean prey mass when compared to the Brookfield area (PLSD $=-5.235, P=0.0007)$, the Ithaca area (PLSD $=-5.038, P=0.0019)$, and the Tug Hill Plateau $(\mathrm{PLSD}=-3.888, P=0.0093)$.

\section{Thrush sampling}

Out of 38 sites, we detected possible breeding by Wood Thrushes, defined as spontaneous vocalizations or vocalizations in response to playback, after Rosenberg et al. (1999) and Hames et al. (2002b), at 12 sites on one visit, and at 7 sites on both visits; at 19 sites no Wood Thrushes were detected on either visit (Table 1). The number of detections varied widely between regions (Fisher's exact test $\chi^{2}=22.73$, df $=6, P=0.0014$ ), with only one Wood Thrush detected during 20 site visits in the Adirondacks compared to the Brookfield State Forest sites, in which 20 site visits yielded 15 detections, and the focal species was detected at all sites at least once.

\section{Empirical Modeling}

We used least squares linear regression on the transformed variables to model the relationship among and between soil properties and the abundance of calcium-rich potential prey items at each site. Soil calcium content was highlysignificantly related to soil $\mathrm{pH}$ as expected, $\left(F_{1,36}=\right.$ $11.833, P=0.0015, R^{2}=0.247$; Fig. 3$)$. There was a marginally nonsignificant effect of the soil calcium content on the number of calcium-rich prey items $\left(F_{1,7}=3.734, P=0.0612, R^{2}=0.094\right.$; Fig. 4$)$. Again, regions differed in this relationship with a strong, positive effect of calcium content in the Ithaca region $\left(F_{1,7}=21.59, P=0.0062, R^{2}=0.8\right)$, and no significant relationships (all $P>0.16$ ) in the other regions. 
Table 1. Detections of Wood Thrushes by region. Each site was visited twice, according to the Birds of Forested Landscapes (BFL) protocol. Distribution of number of detections in each category differed significantly between regions, Fishers exact test $\chi^{2}=22.73$, df $=6, P=0.0014$.

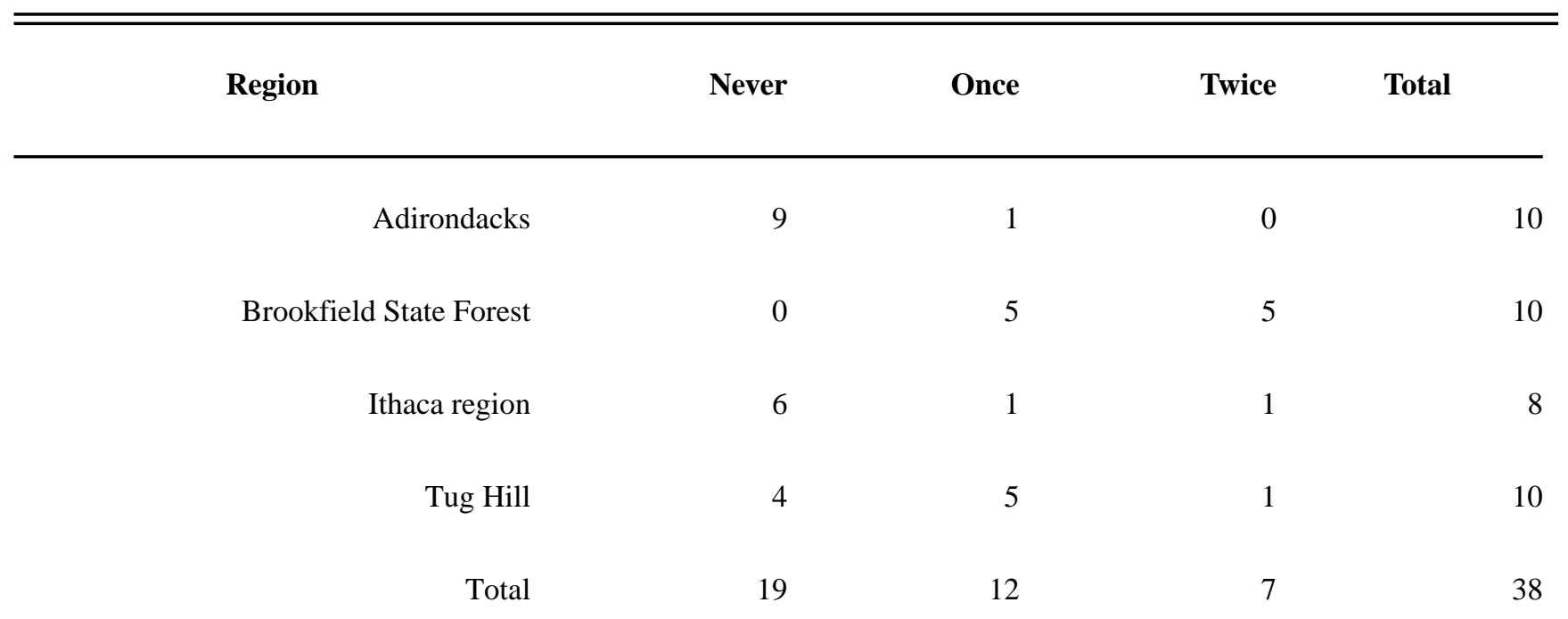

The total abundance of calcium-rich prey items was highly significant and positively related to soil $\mathrm{pH}$ $\left(F_{1,36}=15.472, P=0.0004, R^{2}=0.301 ;\right.$ Fig. 5$)$. The relationship of prey abundance to soil $\mathrm{pH}$ to differed by region with highly significant positive relationships in the Brookfield State Forest $\left(F_{1,7}=\right.$ 19.753, $\left.P=0.0022, R^{2}=0.71\right)$ and Ithaca areas $\left(F_{1,7}=36.725, P=0.0009, R^{2}=0.86\right)$ and no significant relationships in the Adirondacks $\left(F_{1,8}=\right.$ $0.324, P=0.585)$ or the Tug Hill plateau $\left(F_{1,8}=\right.$ $1.514, P=0.2534)$. Overall, the total biomass of all calcium-rich prey was not significantly related to soil pH $\left(F_{1,36}=0.796, P=0.3782, R^{2}=0.02\right)$ or soil calcium content $\left(F_{1,36}=1.592, P=0.2152, R^{2}=\right.$ $0.04)$, although the total mass of invertebrates was highly-significantly related to the abundance of prey $\left(F_{1,36}=15.352, P=0.0004, R^{2}=0.30\right)$.

The relationship between the biomass of calciumrich prey, excluding both slugs and earthworms, $i$. e., myriapods, isopods, and snails, and $\mathrm{pH}$ was not significant $\left(F_{1,36}=0.274, P=0.6039, R^{2}=0.01\right)$. Surprisingly, the relationship between soil calcium content and the mass of calcium-rich prey was highly-significantly negative, driven by the inclusion of the Adirondack sites in which very few calcium-rich prey were found. This relationship is not apparent and not significant $\left(F_{1,36}=2.792, P=\right.$ $0.1047, R^{2}=0.01$ ) when those sites were removed.

We used logistic regression to model the probability of the presence of a breeding Wood Thrush on soil properties, prey abundance, and biomass. Thrush presence was not significantly predicted by either the $\mathrm{pH}\left(\chi^{2}=0.029, P=0.8649\right)$ or the soil's calcium content $\left(\chi^{2}=0.015, P=0.9017\right)$. The thrush's probability of presence was likewise not predicted by the log-transformed total abundance of calciumrich prey at the site $\left(\chi^{2}=0.033, P=0.8554\right)$ nor by the biomass of calcium-rich prey $\left(\chi^{2}=0.431, P=\right.$ $0.5117)$. The probability of a breeding thrush presence given the biomass of calcium-rich prey, but excluding slugs and earthworms, was marginally significant $\left(\chi^{2}=3.656 P=0.056\right.$, AUC $=0.65$; Fig. 6).

This regression model predicted the presence of breeding thrushes moderately well. Using a cut-off predicted probability of $P \geq 0.5$ to indicate the presence of a Wood Thrush breeding attempt 
Fig. 3. The relationship between log-transformed soil calcium content in $\mathrm{mg} / \mathrm{kg}$ and soil $\mathrm{pH}$, measured in water, from each site. Least squares regression yielded a highly significant model: $F_{1,36}=11.833, P=$ $0.0015, R^{2}=0.247$. Line shown represents the predicted best-fit values from the model.

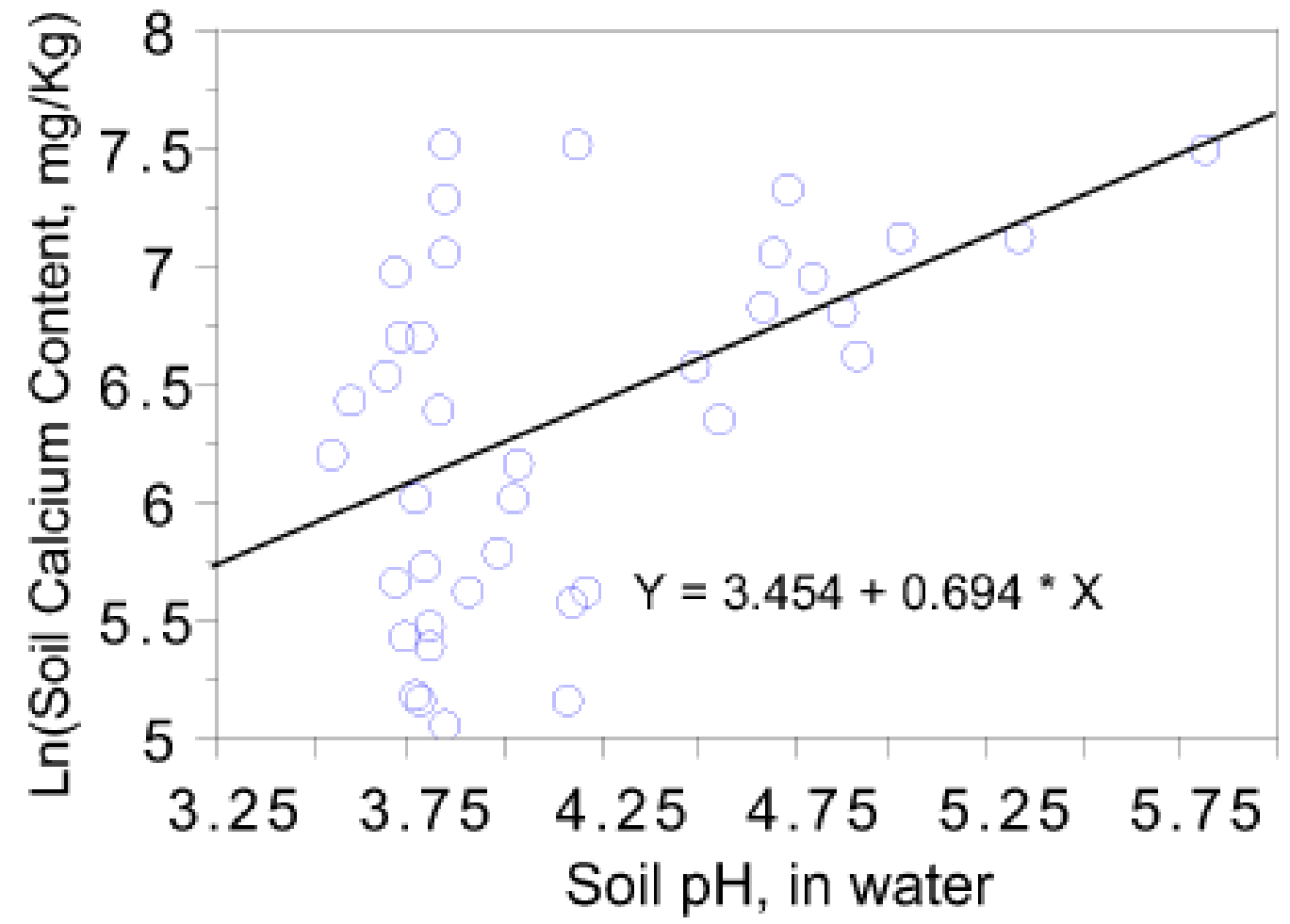

(Hames 2001), the regression model classified sites as occupied or unoccupied better than chance (Table 2 ), correctly classifying $79 \%$ of sites in which the thrush was present. Likewise, the probability of a breeding thrush presence was significantly related to the log-transformed biomass of myriapods at the site $\left(\chi^{2}=4.395, P=0.0361\right.$, AUC $=0.69$; Fig. 7) as predicted by Bures and Weidinger (2003). Again, and also using the significance level of $P \geq 0.5$, the regression model using myriapod mass classified the sites as occupied or unoccupied better than chance (Table 2), correctly classifying $74 \%$ of sites at which the thrush was present.

\section{DISCUSSION}

In nature, synergy between the effects of humancaused change may be the rule rather than the exception, and what we perceive as trends in populations in the wild may be emergent properties of widespread human influences on natural processes, although influences in some cases may offset each other. Understanding the influences of multiple stressors on wild organisms must be based on an understanding of influences, both humanaltered and natural, that occur at multiple geographic extents simultaneously (Levin 1992, Hames 2001). This insight may be made possible by the paradigm described above, whereby finescale studies are used to explore the processes behind large-scale patterns, and are used in turn to generate hypotheses as well as protocols to test these 
Fig. 4. The relationship between the log-transformed total number of calcium-rich prey and the soil calcium content, in $\mathrm{mg} / \mathrm{kg}$, from each site. Ordinary least-squares regression yielded a marginally nonsignificant model: $F_{1,7}=3.734, P=0.0612, R^{2}=0.094$. Line shown represents the predicted best-fit values from the model.

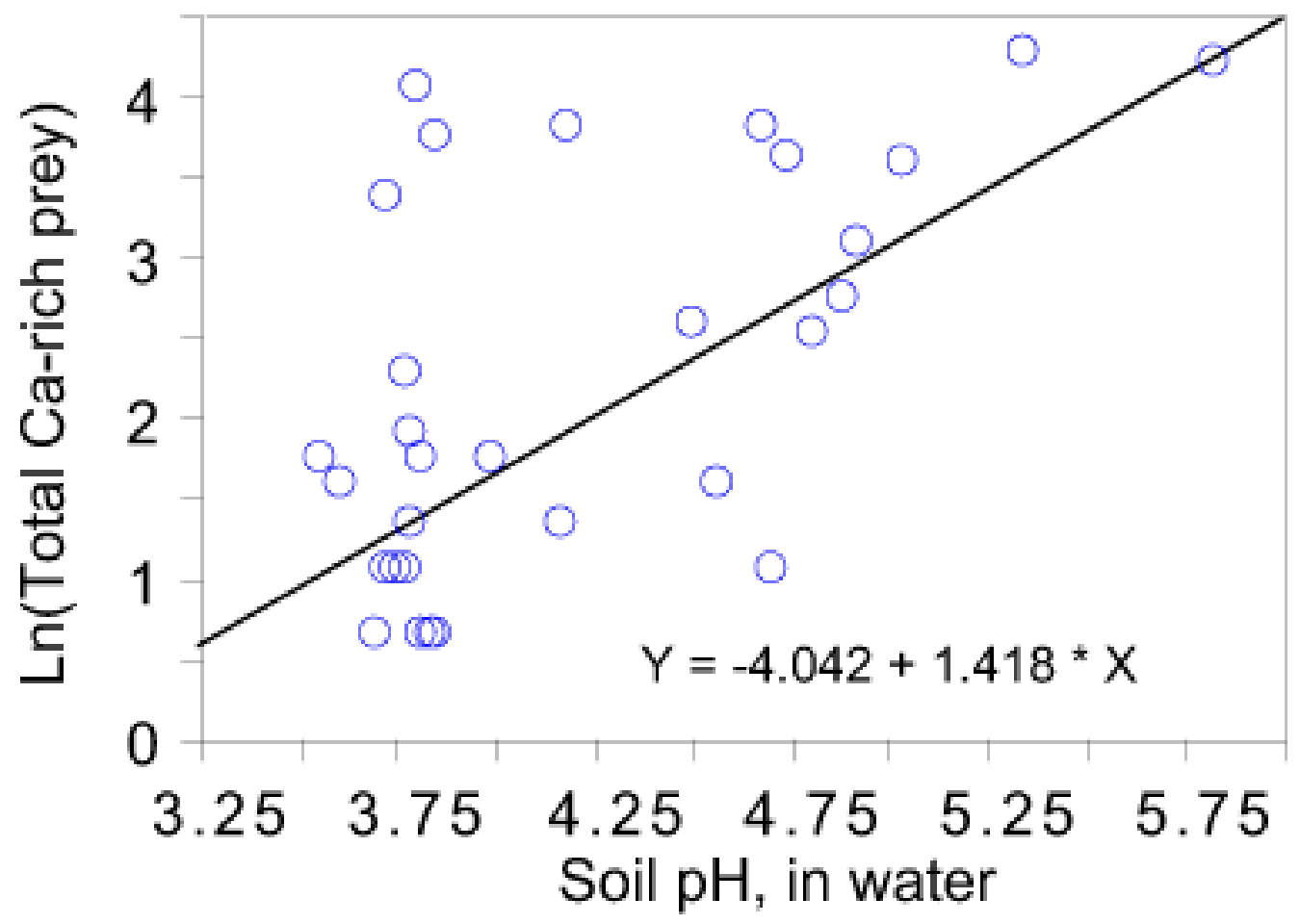

hypotheses using volunteers and other data collection methods at broad scales. This paradigm is exemplified by our current fine-scale research.

Thus, the work that we describe here had two main goals: to explore the relationship between soil properties, the presence and abundance of calciumrich invertebrate prey items, and the presence or absence of breeding Wood Thrushes; and to develop a simple, repeatable, unbiased, and informative protocol to allow volunteers to sample for calciumrich prey at sites over a broad range of fragmentation levels and across the breeding range of the Wood Thrush. The two goals were, of course, interlinked by their ultimate purpose, which was to help understand the processes behind the perceived patterns of Wood Thrush population decline, which are steepest in areas that receive high levels of acidic deposition, and worse in the presence of fragmentation due to an interaction between these two stressors (Hames et al. 2002a).

We postulated that the process behind the perceived patterns of decline in the Wood Thrush population is a decline in calcium-rich prey items in the leaf litter. An abundance of calcium rich prey in the leaf litter, especially in acidified regions, is necessary for successful breeding of litter-foraging birds such as these thrushes. Based on the extensive literature (Esher et al. 1993, Graveland and Vangijzen 1994, Dekhuijzen and Schuijl 1996, Graveland and van de Wal 1996, Nybo et al. 1997, Graveland 1998, Weimer and Schmidt 1998, Zang 1998, Tilgar et al. 1999, Wasson 2002, Fernandez et al. 2003), we 
Fig. 5. The relationship between the log-transformed total number of calcium-rich prey at each site and the soil $\mathrm{pH}$, measured in water. Ordinary least-squares regression yielded a highly significant linear model: $F_{1,36}=15.472, P=0.0004, R^{2}=0.301$. Line shown represents the predicted best-fit values from the model.

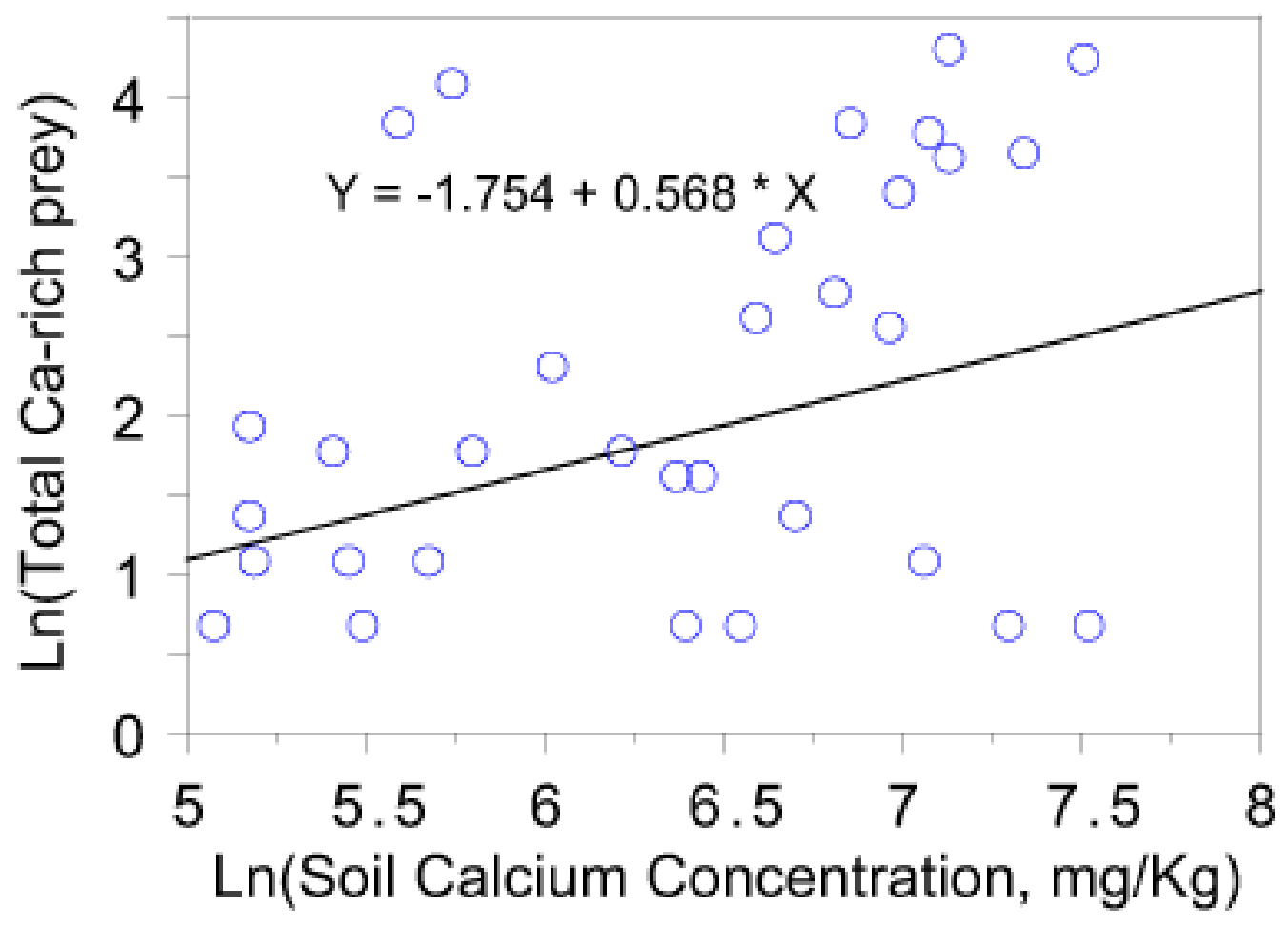

hypothesized that acid rain and depleted soil pools of calcium led to concomitant decreases in calciumrich prey.

Our results are consistent with such a mechanism, with a highly significant and positive relationship between the number of calcium-rich prey and soil $\mathrm{pH}$ overall, driven by extremely strong, highly significant, positive relationships between $\mathrm{pH}$ and prey items in the Brookfield State Forest and Ithaca areas. This relationship is less clear in the Adirondacks and further research is needed. Our results show that this region was frequently the exception with respect to the variables we measured, including the paucity of calcium-rich prey, and the nearly complete absence of Wood Thrushes at low elevations in a region in which they were common, i.e., 40 individuals per fifty-stop Breeding Bird Survey (BBS) routes, as recently as 1966 (Sauer et al. 2004).

Surprisingly, there was only a marginally significant effect of soil calcium content on the number of calcium-rich prey items, which may have been driven by the strong relationship between these variables in the Ithaca region, i.e., the range of soil $\mathrm{pH}$ was largest and the highest $\mathrm{pH}$ values were located in this region. Although our stratified sampling design was successful at capturing a relatively broad range of soil properties, soil $\mathrm{pH}$ was low overall (mean $\pm \mathrm{SE}=4.1510 .088$, median $=$ 3.87 ), and that may have hampered our ability to detect an effect. Interestingly, although the response of calcium-rich prey to soil $\mathrm{pH}$ appears to be a numerical one, Wood Thrushes appear to respond 
Fig. 6. Logistic regression of the presence of a breeding Wood Thrush on the log-transformed mass of calcium-rich prey, excluding slugs. The green circles represent the actual presence (1) or absence (0) of a breeding thrush. The blue diamonds represent the predicted probability of a breeding thrush presence, given the biomass of calcium-rich prey, i.e., snails, isopods and myriapods. The relationship is marginally nonsignificant $(P=0.0559)$, but predicts the presence of Wood Thrushes relatively well, correctly classifying $79 \%$ sites in which a breeding Wood Thrush was present (Table 2). The dashed line represents the cutoff or threshold value: points above or to the right of the line are predicted presences. The green dot at \&\#126 -7.5 represents several sites in which no calcium-rich prey were found.

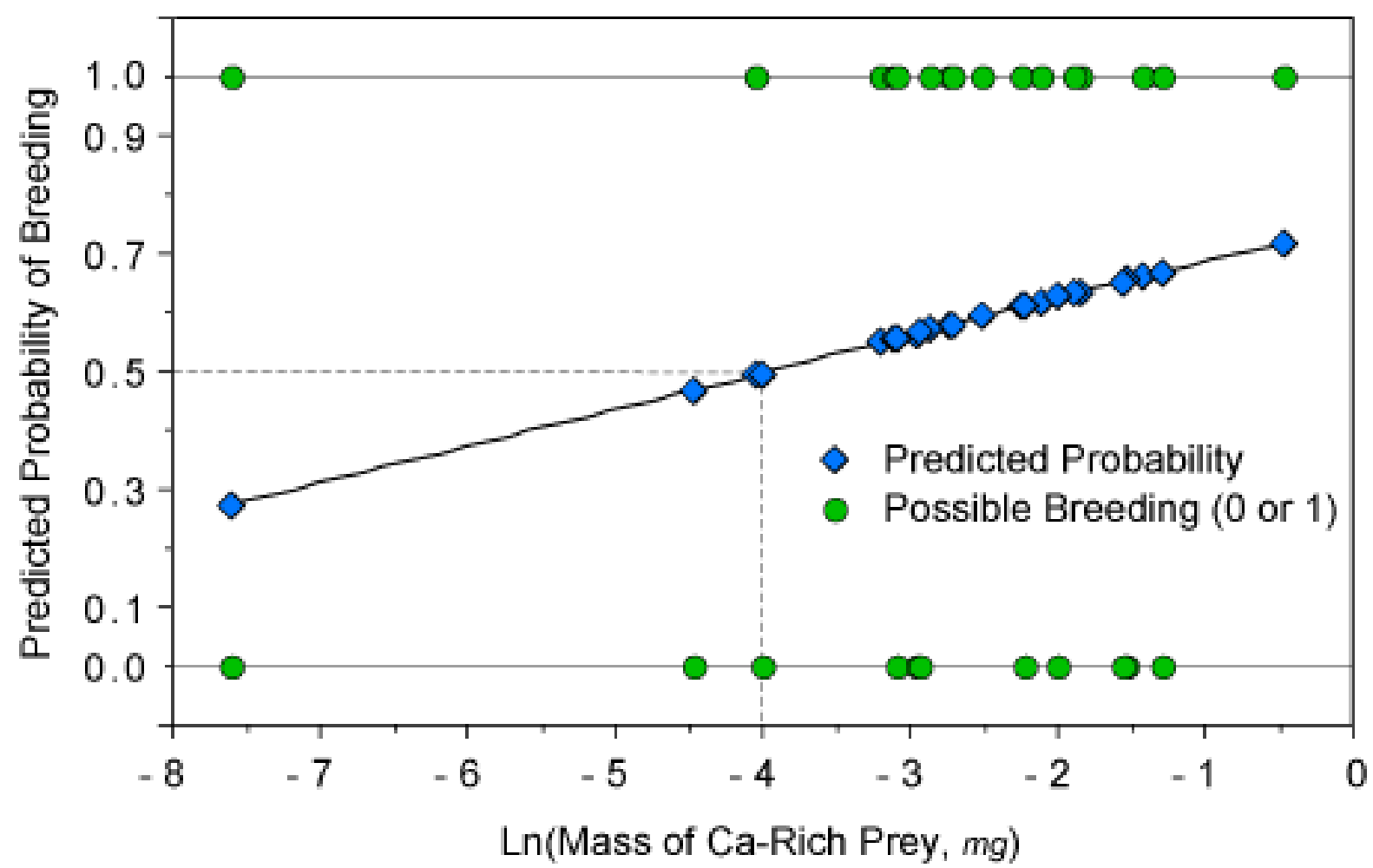

to the available biomass of either total calcium-rich prey or myriapods, excluding slugs, and not their numbers. In any case, total calcium-rich prey biomass is unsurprisingly highly significantly related to the abundance of these potential prey items.

Likewise, the absence of the Wood Thrush from the Adirondacks hampered our ability to use logistic regression to model the presence or absence of focal thrushes, as indicated by the marginally significant $(P=0.036) P$ values for the regression. However, the models we fit were effective classifiers, and we would do well to heed Chatfield's (1995) call to measure the effectiveness of regression models, not merely by statistical significance, but instead by their performance as predictors or classifiers of sites in which presences are found. Seen from this perspective, both logistic regression models performed well. Both did $>20 \%$ better than chance based on Cohen's (1960) Kappa statistic, and both models correctly predicted $>74 \%$ of sites where Wood Thrushes are found, based on the biomass of invertebrates that are high in calcium. 
Fig. 7. Logistic regression of the presence of a breeding Wood Thrush on the log-transformed mass of myriapods. The green circles represent the actual presence (1) or absence (0) of a breeding thrush. The blue circles represent the predicted probability of a breeding thrush presence, given the biomass of myriapods. The relationship is significant $(P=0.0361)$, and predicts the presence of Wood Thrushes relatively well, correctly classifying $74 \%$ sites in which a breeding Wood Thrush was present (Table 2). The dashed line represents the cutoff or threshold value: points above or to the right of the line are predicted presences. The green dot at \&\#126 -7.5 represents several sites in which no calcium-rich prey were found.

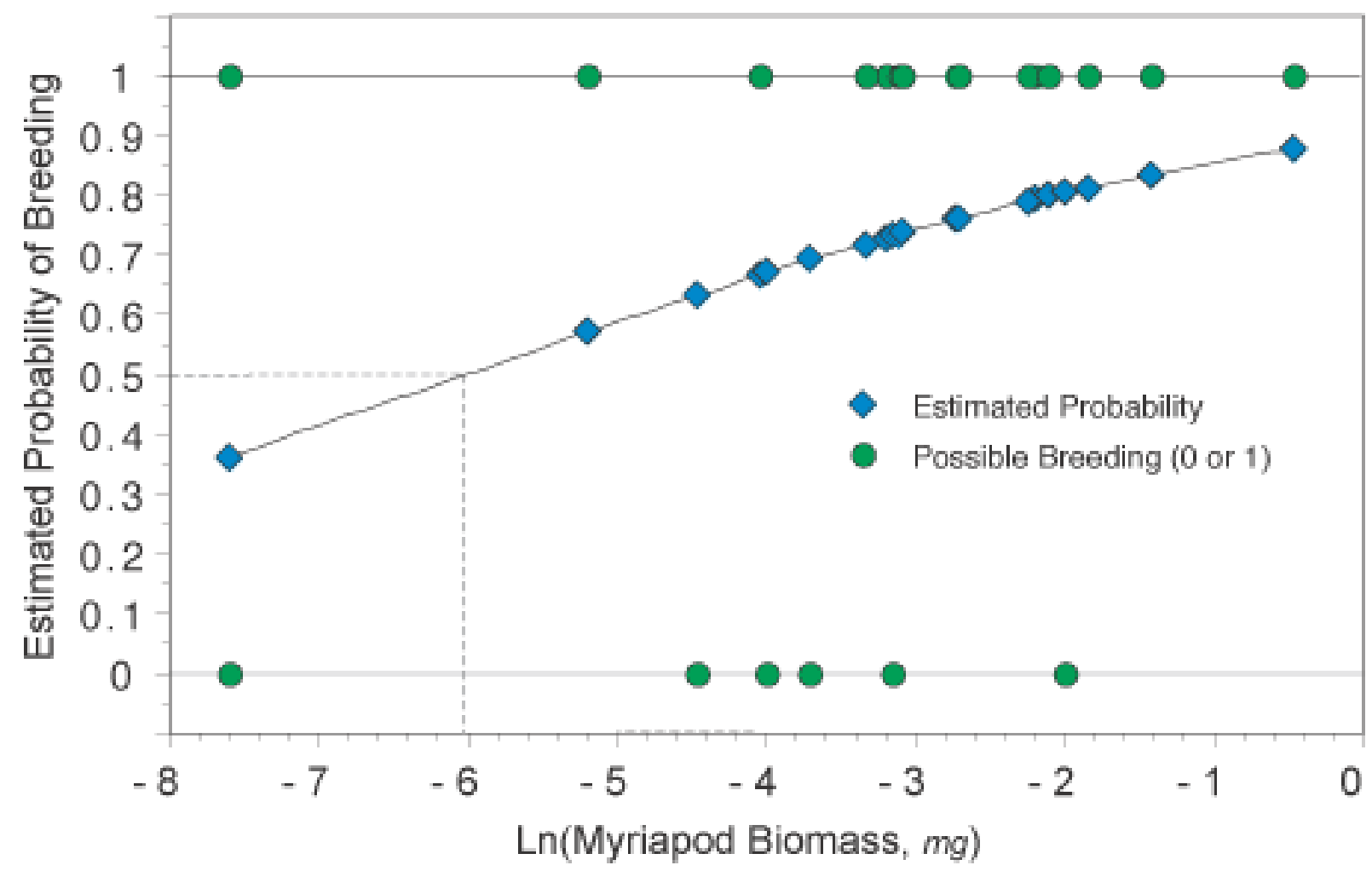

This fine-scaled study did demonstrate that both soil pools of calcium and abundance of calcium-rich prey track soil $\mathrm{pH}$, based on limited invertebrate sampling using an extremely simple and precise method. Further, this study suggests that the presence of Wood Thrushes at a given site was related to the biomass of calcium-rich prey, excluding slugs and earthworms, and in particular, to the biomass of millipedes and centipedes, and not to soil properties per se. This agrees with work by Bures and Weidinger (2003) who showed that isopods and millipedes, which have a calcium content that is three times greater than snail shells, due to their carapaces, which are mainly calcium carbonate, are necessary for breeding in some birds (Graveland and Vangijzen 1994, Dekhuijzen and Schuijl 1996, Bures and Weidinger 2003).

Millipedes, in particular, may be important as calcium-rich prey items because they are easy for birds with thin bills to handle. It is worth noting that of the thrush species in eastern North America that are documented in work by Holmes and Robinson (1988), the Wood Thrush alone takes millipedes as prey, in addition to being the species showing the greatest declines. 
Table 2. Performance of logistic regression models at predicting presence of a breeding Wood Thrush at a study site, given either the biomass of calcium-rich prey, without slugs, or the biomass of myriapods. The measures of performance are based on the confusion matrices tabulating actual and predicted presences (Guisan and Zimmermann 2000). Cohen's Kappa measures the improvement in number of correct classification to the above the number expected to be correctly classified by chance (Cohen 1960). Area under the curve values (AUC) were computed from receiver operating characteristic curves (ROC).

\begin{tabular}{|c|c|c|c|c|c|c|c|c|c|}
\hline $\begin{array}{l}\text { Predicted }= \\
\text { Predictor }\end{array}$ & $\begin{array}{c}\text { Present } \\
\text { Actually } \\
\text { Present }\end{array}$ & $\begin{array}{c}\text { Absent } \\
\text { Actually } \\
\text { Absent }\end{array}$ & $\begin{array}{c}\text { Present } \\
\text { Actually } \\
\text { Absent }\end{array}$ & $\begin{array}{l}\text { Absent } \\
\text { Actually } \\
\text { Present }\end{array}$ & $\begin{array}{l}\text { Present } \\
\text { Correct }\end{array}$ & $\begin{array}{l}\text { Absent } \\
\text { Correct }\end{array}$ & $\mathbf{A U C}$ & $\begin{array}{l}\text { Total \% } \\
\text { Correct }\end{array}$ & $\begin{array}{c}\text { Cohen \% } \\
\text { Kappa }\end{array}$ \\
\hline $\begin{array}{l}\text { Calcium-rich In- } \\
\text { vertebrate Biomass }\end{array}$ & 15 & 9 & 10 & 4 & 0.789 & 0.474 & 0.65 & 63.2 & 26.3 \\
\hline $\begin{array}{l}\text { Myriapod } \\
\text { Biomass }\end{array}$ & 14 & 9 & 10 & 5 & 0.737 & 0.474 & 0.69 & 60.5 & 21.1 \\
\hline
\end{tabular}

Biomass

Our own published work based on the large-scale, volunteer-based BFL study has demonstrated a synergistic or multiplicative interaction between multiple stressors, habitat fragmentation, and acid rain. This current small-scale study suggests that acid rain may affect nesting birds by altering the abundance of calcium-rich prey needed by breeding thrushes as dietary calcium supplements. Further, several authors have noted changes to arthropod communities linked to forest-nonforest edges (Saunders et al. 1991), timber harvest, fragmentation, and small patch sizes (Burke and Nol 1998, Duguay et al. 2000). In particular, Burke and Nol (1988) found a great decrease in the abundance of leaf-litter arthropods, used as prey by the Ovenbird (Seiurus aurocapillus), in habitat fragments.

Interestingly in the present context, Duguay et al. (2000) found that changes due to timber harvest led to a decrease in the abundance of litter-dwelling invertebrates, which was linked to lower nesting success of the Wood Thrush. This provides a testable hypothesis or hypotheses: that calcium-rich prey will be less abundant in smaller patches, closer to forest edges, and in fragmented landscapes that receive heavy acid deposition. Our current study provides a protocol suitable for testing this hypothesis over large geographic extents, using volunteers. This research is ongoing.

\section{Designing and implementing a volunteer-based broadscale study}

The BFL project was designed from the beginning to be extensible and it has already been used to address the effect of human recreation at campgrounds in National Forests (Rosenberg et al. 2004). In addition, it has been extended from the original seven thrush and two accipiter species to over forty species of high conservation concern. A core group of approximately 500 trained and experienced collaborators in BFL have collected data from more than 3500 study sites throughout North America north of the Rio Grande. Further, the methodology, including the ability to playback conspecific vocalizations, augmented by "mobbing" playback, and a point count, used for sampling provides a level playing field by ensuring that 
collaborators of varying skill levels all have a high probability of detecting a bird of the focal species attempting to breed at a given study site. Thus, what remained was the development of a protocol for sampling calcium-rich prey.

Cardboard trapping yielded estimates of prey abundance and biomass that showed relatively strong, significant relationships with soil calcium content and $\mathrm{pH}$, as predicted from the literature. A comparison of the number of prey sampled at each of the two traps within a study site also revealed a strong, highly significant correlation, suggesting that this method provided a precise index of prey abundance. The cardboard trapping process is efficient in the use of researcher time (Hawkins et al. 1998), can be carried out by volunteers based on simple, easy-to-understand instructions, and uses simple materials that can be easily obtained throughout the United States and Canada. This method also samples prey items on the surface or topmost litter layer (Hawkins et al. 1998), where they are most accessible to our focal thrush species (Holmes and Robinson 1988). Because we have had experience trapping at over 40 sites, it was easy to write detailed instructions and provide helpful hints for volunteers based on our own trapping experiences.

During 2003, nearly 70 participants in the largescale pilot project used $\sim 360$ traps to sample for calcium-rich prey at over 180 study sites. Based on comments from collaborators who participated in the large-scale pilot test during the 2004 field season, and interim analysis of the data returned, we decided to include the cardboard trapping of invertebrate prey species to the 2004 and subsequent BFL protocols as an a optional additional step. We modified the materials for clarity and requested that BFL participants include the trapping protocol at one or more of their sites, particularly at sites in which they had previously sampled for Wood Thrushes. Analyses of these data are not complete, but for the 2006 field season, we will use a combination of direct contact with past participants, outreach to bird and conservation clubs, and new recruitment to increase the number of sites in which sampling of calcium-rich invertebrate prey species is carried out.

\section{CONCLUSION}

There are an increasing number of human-caused changes to the environment that may act as multiple stressors of organisms in the wild with effects that, in combination, may be synergistic or multiplicative rather than additive. Understanding such effects may require a combination of data from multiple sources and multiple geographic extents simultaneously, which may be made possible by novel data collection techniques including the participation of volunteer collaborators using carefully designed protocols.

This makes possible a paradigm of alternating extensive studies to document patterns over large geographic extents with intensive studies to document the fine-scale processes leading to the observed patterns. For example, the data derived from this current study suggest that changes caused by acid rain in the soil at the site have knock-on effects on the Wood Thrush, by affecting the abundance and biomass of calcium-rich invertebrate prey needed for successful reproduction. These data also allowed us to test the hypothesis that the paucity of calcium-rich invertebrate prey, linked to acid rain, may be instrumental in population decline in the Wood Thrush, and to generate new hypotheses and a protocol suitable for use by volunteers to test these hypotheses. We have, thus, provided an example of work following this paradigm, based on our ongoing research on the effect of acid rain on thrush and other species breeding in eastern North America. We believe that this technique holds great promise for future research.

Responses to this article can be read online at:

http://www.ecologyandsociety.org/voll1/iss 1/art24/responses/

\section{Acknowledgments:}

The authors gratefully acknowledge the hard work by hundreds of volunteer collaborators who make this research possible. This research was funded by a cooperative agreement between the Cornell Laboratory of Ornithology and the Environmental Protection Agency's Atlantic Ecology Division/ National Health and Environmental Effects Research Laboratory. We are grateful for the assistance and patience of our cooperator, Diane 
Nacci. The Authors wish to thank two anonymous reviewers for their helpful comments. Hames and Lowe also wish to thank their wives for their patience with frequent absences during fieldwork on this project.

\section{LITERATURE CITED}

Andrén, H. 1994. Effects of habitat fragmentation on birds and mammals in landscapes with different proportions of suitable habitat: a review. Oikos 71:355-366.

Baillie, S. R., W. J. Sutherland, S. N. Freeman, R. D. Gregory, and E. Paradis. 2000. Consequences of large-scale processes for the conservation of bird populations. Journal of Applied Ecology 37:88-102.

Bellamy, P. E., S. A. Hinsley, and I. Newton. 1996. Factors influencing bird species numbers in small woods in south-east England. Journal of Applied Ecology 33:249-262.

Blancher, P. J., and D. K. McNicol. 1991. Tree Swallow diet in relation to wetland acidity. Canadian Journal of Zoology 69:2629-2637.

Boulinier, T., J. D. Nichols, J. E. Hines, J. R. Sauer, C. H. Flather, and K. H. Pollock. 2001. Forest fragmentation and bird community dynamics: inference at regional scales. Ecology 82:1159-1169.

Bures, S., and K. Weidinger. 2000. Estimation of calcium intake by Meadow Pipit nestlings in an acidified area. Journal of Avian Biology 31:426-429.

Bures, S., and K. Weidinger. 2003. Sources and timing of calcium intake during reproduction in flycatchers. Oecologia 137:634-641.

Burke, D. M., and E. Nol. 1998. Influence of food abundance, nest-site habitat, and forest fragmentation on breeding ovenbirds. Auk 115:96-104.

Butcher, G. S., and C. R. Smith. 1986. Breeding bird atlases add zip to summer birding. American Birds 40:419-428.

Chatfield, C. 1995. Model uncertainty, data mining, and statistical inference. Journal of the Royal Statistical Society Series A. Statistics in Society 158:419-466.

Cohen, J. 1960. A coefficient of agreement for nominal scales. Educational and Psychological Measurements 20:37-46.

Dekhuijzen, H. M., and G. P. J. Schuijl. 1996. Changes in breeding success of Great Tit Parus major and Pied Flycatcher Ficedula hypoleuca on the Veluwe and the Gooi, 1973-92. Limosa 69:165-174.

Donovan, T. M., P. W. Jones, E. M. Annand, and F. R. Thompson III. 1997. Variation in local-scale edge effects: mechanisms and landscape context. Ecology 78:2064-2075.

Driscoll, C. T., D. Whitall, J. Aber, E. Boyer, M. Castro, C. Cronan, C. L. Goodale, P. Groffman, C. Hopkinson, K. Lambert, G. Lawrence, and S. Ollinger. 2003. Nitrogen pollution in the northeastern United States: sources, effects, and management options. Bioscience 53:357-374.

Duguay, J. P., P. B. Wood, and G. W. Miller. 2000. Effects of timber harvests on invertebrate biomass and avian nest success. Wildlife Society Bulletin 28:1123-1131.

Eeva, T., and E. Lehikoinen. 1998. Local survival rates of the pied flycatchers (Ficedula hypoleuca) and the great tits (Parus major) in an air pollution gradient. Ecoscience 5:46-50.

Esher, R. J., R. L. Baker, S. J. Ursic, and L. C. Miller. 1993. Responses of invertebrates to experimental acidification of the forest floor under southern pines. Pages 75-83 in J. R. Longcore and G. F. Sepik, editors. Proceedings of the Eighth American Woodcock Symposium. U.S. Fish and Wildlife Service Biological Report Number 16. Washington, D.C., USA.

Fair, J. M., and R. E. Ricklefs. 2002. Physiological, growth, and immune responses of Japanese quail chicks to the multiple stressors of immunological challenge and lead shot. Archives of Environmental Contamination and Toxicology 42:77-87.

Fernandez, I. J., L. E. Rustad, S. A. Norton, J. S. Kahl, and B. J. Cosby. 2003. Experimental 
acidification causes soil base-cation depletion at the Bear Brook Watershed in Maine. Soil Science Society of America Journal 67:1909-1919.

Graveland, J. 1996. Avian eggshell formation in calcium-rich and calcium-poor habitats: importance of snail shells and anthropogenic calcium sources. Canadian Journal of Zoology 74:1035-1044.

Graveland, J. 1998. Effects of acid rain on bird populations. Environmental Reviews 6:41-54.

Graveland, J., and R. H. Drent. 1997. Calcium availability limits breeding success of passerines on poor soils. Journal of Animal Ecology 66:279-288.

Graveland, J., and R. van der Wal. 1996. Decline in snail abundance due to soil acidification causes eggshell defects in forest passerines. Oecologia 105:351-360.

Graveland, J., R. van der Wal, J. H. Vanbalen, and A. J. Vannoordwijk. 1994. Poor reproduction in forest passerines from decline of snail abundance on acidified soils. Nature 368:446-448.

Graveland, J., and T. Vangijzen. 1994. Arthropods and seeds are not sufficient as calcium sources for shell formation and skeletal growth in passerines. Ardea 82:299-314.

Gunn, J. S., A. Desrochers, M. A. Villard, J. Bourque, and J. Ibarzabal. 2000. Playbacks of mobbing calls of Black-capped Chickadees as a method to estimate reproductive activity of forest birds. Journal of Field Ornithology 71:472-483.

Hall, B. D., and V. L. St. Louis. 2004. Methylmercury and total mercury in plant litter decomposing in upland forests and flooded landscapes. Environmental Science and Technology 38:5010-5021.

Hames, R. S. 2001. Habitat fragmentation and forest birds: effects at multiple scales. Dissertation. Cornell University, Ithaca, New York, USA.

Hames, R. S., K. V. Rosenberg, J. D. Lowe, S. E. Barker, and A. A. Dhondt. $2002 a$. Adverse effects of acid rain on the distribution of the Wood Thrush Hylocichla mustelina in North America. Proceedings of the National Academy of Sciences of the United States of America 99:11235-11240.
Hames, R. S., K. V. Rosenberg, J. D. Lowe, S. E. Barker, and A. A. Dhondt. 2002b. Effects of forest fragmentation on North American tanager and thrush species in eastern and western landscapes. Studies in Avian Biology 25:81-92.

Hames, R. S., K. V. Rosenberg, J. D. Lowe, and A. A. Dhondt. 2001. Site reoccupation in fragmented landscapes: testing predictions of metapopulation theory. Journal of Animal Ecology 70:182-190.

Hawkins, J. W., M. W. Lankester, R. A. Lautenschlager, and F. W. Bell. 1997. Lengthbiomass and energy relationships of terrestrial gastropods in northern forest ecosystems. Canadian Journal of Zoology 75:501-505.

Hawkins, J. W., M. W. Lankester, and R. R. A. Nelson. 1998. Sampling terrestrial gastropods using cardboard sheets. Malacologia 39:1-9.

Heugens, E. H. W., A. J. Hendriks, T. Dekker, N. M. van Straalen, and W. Admiraal. 2001. A review of the effects of multiple stressors on aquatic organisms and analysis of uncertainty factors for use in risk assessment. Critical Reviews in Toxicology 31:247-284.

Holmes, R. T., and S. K. Robinson. 1988. Spatial patterns, foraging tactics, and diets of groundforaging birds in a northern hardwoods forest. Wilson Bulletin 100:377-394.

James, F. C., C. E. McCullogh, and D. A. Wiedenfeld. 1996. New approaches to the analysis of population trends in land birds. Ecology 77:13-27.

Lamb, D., and V. Bowersox. 2000. The national atmospheric deposition program: an overview. Atmospheric Environment 34:1661-1663.

Landis, W. G. 2003. Twenty years before and hence: ecological risk assessment at multiple scales with multiple stressors and multiple endpoints. Human and Ecological Risk Assessment 9:1317-1326.

Lee, M., L. Fahrig, K. Freemark, and D. J. Currie. 2002. Importance of patch scale vs. landscape scale on selected forest birds. Oikos 96: $110-118$.

Levin, S. A. 1992. The problem of pattern and scale 
in ecology. Ecology 73:1943-1967.

Mand, R., and V. Tilgar. 2003. Does supplementary calcium reduce the cost of reproduction in the Pied Flycatcher Ficedula hypoleuca? Ibis 145:67-77.

Manel, S., H. C. Williams, and S. J. Ormerod. 2001. Evaluating presence-absence models in ecology: the need to account for prevalence. Journal of Applied Ecology 38:921-931.

McCoy, K. D. 1999. Sampling terrestrial gastropod communities: using estimates of species richness and diversity to compare two methods. Malacologia 41:271-281.

Moore, D. R. J. 2001. The Anna Karenina principle applied to ecological risk assessments of multiple stressors. Human and Ecological Risk Assessment 7:231-237.

Nybo, S., M. Staurnes, and K. Jerstad. 1997. Thinner eggshells of dipper (Cinclus cinclus) eggs from an acidified area compared to a non-acidified area in Norway. Water Air and Soil Pollution 93:255-266.

Oggier, P., S. Zschokke, and B. Baur. 1998. A comparison of three methods for assessing the gastropod community in dry grasslands. Pedobiologia 42:348-357.

Paton, P. W. C. 1994. The effect of edge on avian nest success: how strong is the evidence? Conservation Biology 8:17-26.

Patuxent Wildlife Research Center. 2000. North American breeding bird survey ftp data set. USGS, Patuxent, Laurel, Maryland, USA.

Rosenberg, K. V., B. Kott, R. S. Hames, J. Rohrbaugh, R. W., S. E. Barker Swarthout, and J. D. Lowe. 2004. Effects of recreational development on forest-breeding birds in U.S. National Forests. Final Report to the USDA Forest Service. Challenge Cost Share Agreement Number 98-CCS-197. Cornell Laboratory of Ornithology, Ithaca, New York, New York, USA.

Rosenberg, K. V., J. D. Lowe, and A. A. Dhondt. 1999. Effects of forest fragmentation on breeding tanagers: a continental perspective. Conservation Biology 13:568-583.
Roth, R. R., M. S. Johnson, and T. J. Underwood. 1996. Wood Thrush (Hylocichla mustelina). In A. Poole and F. Gill, editors. The birds of North America, Number 246. The Academy of Natural Sciences, Philadelphia, Pennsylvania, USA.

SAS Institute. 1996. SAS/STAT software: changes and enhancements through release 6.11. SAS Institute, Cary, North Carolina, USA.

SAS Institute. 1998. Statview. SAS institute, Cary, North Carolina, USA.

Sauer, J. R., J. E. Hines, and J. Fallon. 2001. The North American breeding bird survey results and analysis 1966-2000. Patuxent Wildlife Research Center, Laurel, Maryland, USA.

Sauer, J. R., J. E. Hines, and J. Fallon. 2004. The North American breeding bird survey results and analysis 1966-2003. Patuxent Wildlife Research Center, Laurel, Maryland, USA.

Saunders, D.A., R. J. Hobbs, and C. R. Margules. 1991. Biological consequences of ecosystem fragmentation: a review. Conservation Biology 5:18-32.

Scheuhammer, A. M. 1991. Effects of acidification on the availability of toxic metals and calcium to wild birds and mammals. Environmental Pollution 71:329-375.

Scheuhammer, A. M. 1996. Influence of reduced dietary calcium on the accumulation and effects of lead, cadmium, and aluminum in birds. Environmental Pollution 94:337-343.

Sih, A., A. M. Bell, and J. L. Kerby. 2004. Two stressors are far deadlier than one. Trends in Ecology and Evolution 19:274-276.

Silver, T. M., and T. D. Nudds. 1995. Influence of low-level cadmium and reduced calcium intake on tissue $\mathrm{Cd}$ concentrations and behavior of American Black ducks. Environmental Pollution 90:153-161.

Spalding, M. G., P. C. Frederick, H. C. McGill, S. N. Bouton, L. J. Richey, I. M. Schumacher, C. G. M. Blackmore, and J. Harrison. 2000. Histologic, neurologic, and immunologic effects of methylmercury in captive great egrets. Journal of Wildlife Diseases 36:423-435. 
St. Louis, V. L., and J. C. Barlow. 1993. The reproductive success of tree swallows nesting near experimentally acidified lakes in northwestern Ontario. Canadian Journal of Zoology 71:1090-1097.

St. Louis, V. L., and L. Breebaart. 1991. Calcium supplements in the diet of nestling tree swallows near acid sensitive lakes. Condor 93:286-294.

St. Louis, V. L., L. Breebaart, J. C. Barlow, and J. F. Klaverkamp. 1993. Metal accumulation and metallothionein concentrations in tree swallow nestlings near acidified lakes. Environmental Toxicology and Chemistry 12:1203-1207.

Tilgar, V., R. Mand, and A. Leivits. 1999. Effect of calcium availability and habitat quality on reproduction in Pied Flycatcher Ficedula hypoleuca and Great Tit Paras major. Journal of Avian Biology 30:383-391.

U.S. Forest Service (USDA/NRCS). 1994. State soil geographic (STATSGO) data base: data use information. Miscellaneous Publication 142, USDA Natural Resources Conservation Service, National Soil Survey Center, Washington, D.C., USA.

Wasson, M. F. 2002. Causes and consequences of calcium limitation in breeding passerine birds. Dissertation. Cornell University, Ithaca, New York, USA.

Weathers, K. C., M. L. Cadenasso, and S. T. A. Pickett.2001. Forest edges as nutrient and pollutant concentrators: potential synergisms between fragmentation, forest canopies, and the atmosphere. Conservation Biology 15:1506-1514.

Weathers, K. C., G. M. Lovett, and G. E. Likens. 1995. Cloud deposition to a spruce forest edge. Atmospheric Environment 29:665-672.

Weimer, V., and K. H. Schmidt. 1998. Studies on the egg quality of the Great Tit (Parus major) in relation to soil-condition. Journal Fur Ornithologie 139:3-9.

Zang, H. 1998. Effects of "acid rain" on a population of Great Tit (Parus major) in the higher regions of the Harz mountains. Journal Fur Ornithologie 139:263-268. 